\title{
Trends and Associated Factors of Maternal Mortality in Zambia: Analysis of Routinely Collected Data (2015-April 2019)
}

\author{
Nedah Chikonde Musonda ${ }^{1}$, Mumbi Chola ${ }^{2}$, Patrick Kaonga ${ }^{1}$, Samson Shumba $^{1}$, Choolwe Jacobs $^{1}$ \\ ${ }^{1}$ Department of Epidemiology \& Biostatistics, School of Public Health, University of Zambia, Lusaka, Zambia \\ ${ }^{2}$ Field Implementation Unit, ZAMPHIA Survey, Maryland Global Initiatives Corporation (MGIC), Lusaka, Zambia
}

\section{Email address:}

mnedah@yahoo.com (N. C. Musonda), mumbi24@gmail.com (M. Chola), patrickkaonga@gmail.com (P. Kaonga), samsonshumba1@gmail.com (S. Shumba),choolwe2003@yahoo.com (C. Jacobs)

${ }^{*}$ Corresponding author

\section{To cite this article:}

Nedah Chikonde Musonda, Mumbi Chola, Patrick Kaonga, Samson Shumba, Choolwe Jacobs. Trends and Associated Factors of Maternal Mortality in Zambia: Analysis of Routinely Collected Data (2015-April 2019). Journal of Gynecology and Obstetrics.

Vol. 9, No. 5, 2021, pp. 155-161. doi: 10.11648/j.jgo.20210905.14

Received: July 30, 2021; Accepted: August 19, 2021; Published: September 30, 2021

\begin{abstract}
Introduction: Reduction of maternal mortality is a global priority. Based on one of Sustainable Development Goal target, Zambia aims to improve maternal health and one of the top priorities is to reduce maternal mortality ratio (MMR) to less 70 per 100,000 live births by 2030. Tracking progress towards set targets remains critical to guide policy and program implementation. This study aimed at assessing the trends and associated factors of maternal mortality in Zambia from April 2015 to April 2019. Methods: Data on maternal deaths was collected from the maternal surveillance database from April 2015April 2019 from the 9 provinces of Zambia. Data was aggregated and coded in excel then merged. Incident rate ratios were reported using Zero Truncated Poisson (ZTP) regression. All analysis was done in 2021 using STATA version 14.2. Results: A total of 1,461 maternal deaths were reviewed. The trends of maternal deaths in the four-year period have not been consistently high or low but steadily following an upward trend with no significant downward trend. A multivariable ZTP model showed that women in Luapula (IRR 0.21 95\% CI; 0.07-0.58), Western (IRR $0.4495 \%$ CI; 0.24-0.81) and Lusaka (IRR 0.07 95\% CI; 0.001-0.51) provinces had a reduced IRR of maternal deaths compared to women in Central province $(\mathrm{P}<0.05)$. The findings also showed that the age group 20-29 and 30-39 years had an increased IRR of maternal death compared to the age group less than 20 years $(\mathrm{p}<0.05$ ). Sepsis, (aIRR 0.14 95\% CI; 0.3-0.57), Hypertensive disorders (aIRR $0.2095 \%$ CI; 0.07-0.61) and indirect causes (aIRR $0.2295 \% \mathrm{CI}$; 0.08-0.63) in the study had a reduced IRR compared to women who had abortions $(\mathrm{P}<0.05)$. However, women who had live births controlling for other variables had an increased IRR (aIRR $4.7595 \% \mathrm{CI}$; 1.5614.43) compared to those who had abortions $(\mathrm{P}<0.05)$. There was no sufficient evidence to suggest HIV was associated with maternal deaths $(\mathrm{P}=0.24)$. Conclusion: The findings in this study shows that, in Zambia, maternal deaths over the years have not had a significant decline, thus provides evidence for re-strategizing, planning, policy formulation and implementation for reproductive health programmes to reduce maternal deaths in Zambia.
\end{abstract}

Keywords: Maternal Mortality, Maternal Death, Sepsis, Hypertensive Disorders

\section{Background}

World Health Organisation (WHO) defines maternal mortality as death of a woman while pregnant or within 42 days of termination of pregnancy irrespective of duration or site of the pregnancy from any cause related to or aggravated by the pregnancy or its management but not from incidental or accidental causes [1].

According to UN inter-agency estimates, from 2000-2017, the global maternal mortality ratio declined by 38 per cent, from 342 deaths to 211 deaths per 100,000 live births [2]. However, over the years, there has been progress in reducing maternal mortality with global galvanized efforts. The global MMR in 2017 is estimated at 211 maternal deaths per 
100,000 live births, representing a $38 \%$ reduction since 2000 , when it was estimated at 342. With an average Annual Rate of Reduction (AAR) at $2.9 \%$ entailing that the MMR declined by $2.9 \%$ every year between $2000-2017$ [2]. Despite the decline, developing countries account for $99 \%$ of the deaths. Sub-Saharan Africa and South Asia alone accounted for $87 \%$ of global maternal deaths. In Sub-Saharan Africa, one in every 160 women dies of pregnancy related causes during her lifetime, compared with only 1 in 3700 women in developed countries [3].

MMRs are different between geographical regions, developed and developing countries. Timely identification and appropriate management of factors that increase the risk of maternal morbidity to mortality have the potential to improve pregnancy care and to prevent deaths. Several previous studies have identified a number of factors that are thought to contribute to an increased risk of progression from severe maternal morbidity to death, such as being HIV positive, hypertensive disorders, inadequate antenatal care, and suboptimal clinical care during delivery and postpartum. Trends of maternal deaths in Malawi showed an increase between 1980 and 1990 (from 317/100,000-748/100,000), however reached a peak in $1997(971 / 100,000)$ and started declining between 2005 and 2010 from 846/100,000 to $484 / 100,000$ in 2010 [4].

In Zambia, MMR has been fluctuating with no steady decrease. In 1990, MMR was 577/100,000, this later increased to $596 / 100,000$ in 1995 . It increased further from $649 / 100,000$ in 1996 to $729 / 100,000$ in 2001-02. In 2013-14 a decrease was recorded in MMR to 398 deaths per 100,000 live births [5]. The annual rate of reduction varied in rural and urban areas in the provinces. The disparities in the ratios could have been related to the geographical variation and differences in socio-economic, environmental, and demographic features. According to WHO (2014), Zambia stands at 1 in 59 women likely to experience the risk of dying from maternal causes in estimated lifetime risk of maternal deaths.

According to the Zambia National Health Strategic Plan (ZNHSP) improving maternal health is one of the top priority focus areas for the Government of the Republic of Zambia with reduction of maternal mortalities a major target to less than $100 / 100,000$ live births by 2021 [6]. Sustainable Development Goal 3.1 (SDGs 3.1) target is to reduce MMR to less than 70 per 100,000 live births by 2030 [7]. Zambia has invested resources in maternal health, which has seen a reduction in maternal mortality from 398 in 2013-2014 to 278 in 2018 (CSO 2019).

Despite having a number of health facilities, trained staff, and interventions like Emergency Neonatal and Obstetric care (EmONC), MDSR, Saving Mothers Giving Life (SMGL) and Safe Motherhood Action Groups (SMAG), trends and associated factors for MMR using real time data is not well known. The study aimed to evaluate the trends and determine factors contributing to maternal mortality in Zambia.

\section{Methods}

This study was a cross-sectional study of all maternal deaths reported and submitted to Ministry of Health $(\mathrm{MoH})$ in the maternal surveillance database from April 2015-April 2019. The study was done from 2019-2021. Records of pregnant women that died due to incidental or accidental causes were excluded. These were deaths that occurred due to road traffic accidents, pushes, or falls and those that occurred due to any incidences that pose a danger to the mother's life such as a snake bite, accidental poisoning, or suicide. A complete enumeration of all maternal deaths was done.

Maternal mortality data was aggregated into 6 monthly periods in excel and exported to STATA version 14.2 (StataCorp, College Station, Texas, USA) for analysis. Normality of the data (maternal death) was checked using Shapiro Wilk test. Trends for maternal deaths from April 2015-April 2019 graph was done in excel.

Kruskal Wallis and Ranksum tests were used in the analysis to determine association between maternal death, demographic, and clinical factors. To investigate the factors that predicted maternal death, Zero Truncated Poisson Regression (ZTPR) was used for analysis, as the outcome variable (maternal death) had no zeros. The likelihood ratio test, the AIC and BIC were used to come up with the best model. P-value $<0.05$ was considered significant. This study was approved by the University of Zambia Biomedical Research Ethics Committee (UNZABREC- ref: 246-2019) and National Health Research Authority (NHRA).

\section{Results}

\subsection{Characteristics and Associated Factors of Maternal Deaths - April 2015 to April 2019}

Table 1 shows the characteristics and associated factors of maternal deaths. Eastern province recorded 16.71\% $(183 / 1095)$ the highest number of maternal deaths and whereas Northern Province had had the lowest at $1.74 \%$ (19/1095). Among the deaths, those that had an HIV positive result accounted for $76.87 \%(638 / 830)$ while those that were HIV negative were $23.13 \%$ (192/830). Haemorrhage accounted for the highest number of deaths at $40.12 \%$ (386/962), while obstructed labour accounted for the least cause of death at $0.83 \%(8 / 962)$. The age group 20-29 years had the highest number of deaths at $39.41 \%$ (426/1081); however, age group 40-49 years accounted for $8.79 \%(95 / 1081)$ least deaths. On the outcome of pregnancy, the live babies had the highest percentage of maternal deaths at $41.51 \%(379 / 913)$ while abortions were the lowest at $7.89 \%(72 / 913)$. Province, age category, pregnancy outcome and causes of death were associated with maternal death $(\mathrm{p}<0.05)$. However, findings revealed no evidence of an association between maternal death and HIV status $(\mathrm{P}=0.85)$. 
Table 1. Characteristics and associated factors of maternal deaths - April 2015 to April 2019.

\begin{tabular}{|c|c|c|c|}
\hline Characteristic & Maternal death & Percentage (\%) & p-value \\
\hline \multicolumn{4}{|l|}{ Age $(n=1081)$} \\
\hline $10-19$ years & 147 & 13.60 & \multirow{4}{*}{$0.003^{\mathrm{K}}$} \\
\hline $20-29$ years & 426 & 39.41 & \\
\hline $30-39$ years & 413 & 38.21 & \\
\hline $40-49$ years & 95 & 8.79 & \\
\hline \multicolumn{4}{|l|}{ Province $(\mathrm{n}=1,095)$} \\
\hline Central & 135 & 12.33 & \multirow{9}{*}{$<0.0001^{\mathrm{K}}$} \\
\hline Copperbelt & 158 & 14.43 & \\
\hline Eastern province & 183 & 16.71 & \\
\hline Luapula & 158 & 14.43 & \\
\hline Lusaka & 132 & 12.05 & \\
\hline Northwestern & 37 & 3.38 & \\
\hline Northern & 19 & 1.74 & \\
\hline Southern & 139 & 12.69 & \\
\hline Western & 134 & 12.24 & \\
\hline \multicolumn{4}{|l|}{ HIV status $(\mathrm{n}=830)$} \\
\hline Negative & 638 & 76.87 & \multirow{2}{*}{$0.85^{\mathrm{R}}$} \\
\hline Positive & 192 & 23.13 & \\
\hline \multicolumn{4}{|l|}{ Cause of Death ( $\mathrm{n}=962)$} \\
\hline Abortions & 37 & 3.85 & \multirow{6}{*}{$0.04^{\mathrm{K}}$} \\
\hline Haemorrhage & 386 & 40.12 & \\
\hline Hypertensive disorders & 144 & 14.97 & \\
\hline Obstructed labour & 8 & 0.83 & \\
\hline Sepsis & 123 & 12.79 & \\
\hline Others & 264 & 27.44 & \\
\hline \multicolumn{4}{|c|}{ Pregnancy outcome $(\mathrm{n}=913)$} \\
\hline Abortion & 72 & 7.89 & \multirow{5}{*}{$<0.0001^{\mathrm{K}}$} \\
\hline Fresh still birth & 211 & 23.11 & \\
\hline Live baby & 379 & 41.51 & \\
\hline Macerated still birth & 95 & 10.41 & \\
\hline Others-undelivered & 156 & 17.09 & \\
\hline
\end{tabular}

Others $=$ Other indirect causes; $\mathrm{K}=$ Kruskal Wallis; $\mathrm{R}=$ Ranksum test

Figure 1 shows that maternal death in 2015 had an upward trend by mid-year followed by a steady downward trend in the mid and last months of 2016, there was a reduction in the first 3 months, became steady from the $4^{\text {th }}$ to the and $9^{\text {th }}$ months. In the last 3 months of 2016, there was a sharp rise and decline in maternal death. The year 2017 recorded the least number of maternal deaths compared to any other year, which was steady across all the months. On the other hand, 2018 recorded the highest numbers of maternal deaths, which was only steady in the $4^{\text {th }}$ to the $9^{\text {th }}$ months of the year. The beginning of 2019 had an upward trend with a steady trend in the following three months. Over a four-year period, the figure shows an up and downward trend in the deaths with steadily low trends in the last months of the years.

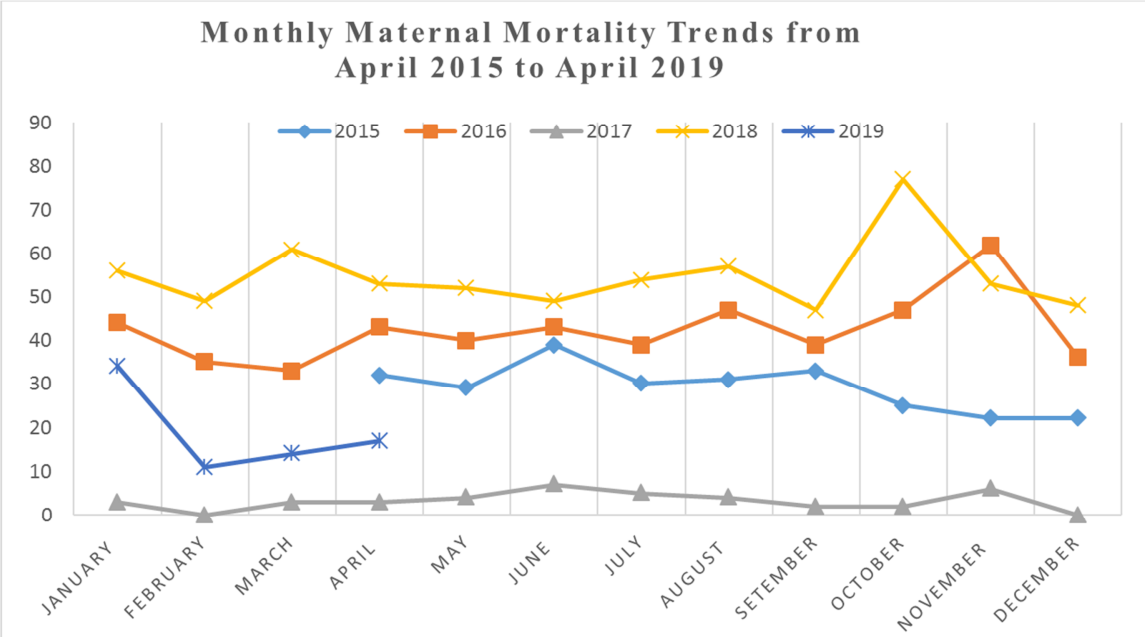

Figure 1. Trends of Maternal Mortality from April 2015 - April 2021. 


\subsection{Bivariate and Multivariable Zero Truncated Poisson (ZTP) Regression}

Results in Table 2 show that age, pregnancy outcome, and province were predictors of maternal deaths in bivariate analysis $(p<0.05)$. However, only Luapula and Southern provinces were significantly different from Central province.

In multivariable analysis Table 2, age, pregnancy outcome, provinces and cause of death were predictors of maternal death $(\mathrm{p}<0.05)$. Controlling for other factors, women aged 20-29 years had 3.67 times increased incident rate ratio compared to women less than 20 years $(95 \% \mathrm{CI}$; $1.5-9.03$; $\mathrm{P}<0.0001)$. Similarly, women aged 30 to 39 years of age had 4.08 times increased IRR compared to women less than 20 years $(95 \% \mathrm{CI} ; 1.67-9.96 ; \mathrm{P}<0.005)$. The findings also suggests that women aged 30 to 39 years had an increased IRR compared to women aged 20-29 years.

The results in both the bivariate and multivariable model suggest that women who gave birth to live babies had an increased IRR compared to women who had abortions as a pregnancy outcome (IRRc; 3.14; CI 95\%; 1.48 - 6.63; $\mathrm{P}<0.005$ ) and (IRRa 4.75; CI 95\%: $1.56-14.43$; $\mathrm{p}<0.05$ ). However, controlling for other variables, there was no evidence to suggest those with fresh births, macerated stillbirths and undelivered had an IRR different from those who had abortions ( $p>0.05)$. Controlling for all other factors, women in Luapula province had a 0.21 times decreased IRR of maternal death compared to women in central province $(95 \%$ CI; $0.07-0.58 ; \mathrm{p}<0.005)$. Women who had hypertension and sepsis had a reduced IRR of maternal death compared to those that had an abortion $(\mathrm{aIRR}=0.2 ; 95 \%$ CI $0.07-0.61$; $\mathrm{P}=0.005$ ) and (aIRR $=0.14 ; 95 \%$ CI $0.3-0.57 ; \mathrm{P}=0.006$ ) respectively. Considering age, cause of death, province and pregnancy outcome, results suggest that HIV Negative women had an increased IRR (1.32 times) of maternal death compared to HIV positive women $(95 \%$ CI; $0.83-2.08$; $\mathrm{p}>0.24)$. However, we could not rule out chance finding $(\mathrm{p}>0.05)$.

Table 2. Bivariate and Multivariable Zero Truncated Poisson (ZTP) Regression.

\begin{tabular}{|c|c|c|c|c|}
\hline Variables & $\operatorname{cIRR}(95 \% \mathrm{CI})$ & P-value & $\operatorname{aIRR}(95 \% \mathrm{CI})$ & P-value \\
\hline \multicolumn{5}{|l|}{ Age (years) } \\
\hline $\operatorname{Ref}<20$ & $\operatorname{Ref}^{1}(1)$ & & $\operatorname{Ref}(1)$ & \\
\hline $30-39$ & $2.63(1.69-4.09)$ & $<0.0001$ & $4.08(1.67-9.96)$ & 0.002 \\
\hline $40-49$ & $0.89(0.44-1.78)$ & 0.739 & $0.98(0.29-3.32)$ & 0.97 \\
\hline \multicolumn{5}{|l|}{ Pregnancy Outcome: } \\
\hline Fresh Still Birth & $1.40(0.62-3.15)$ & 0.42 & $1.75(0.56-5.43)$ & 0.34 \\
\hline Live baby & $3.14(1.48-6.63)$ & 0.003 & $4.75(1.56-14.43)$ & 0.006 \\
\hline Macerated Still Birth & $0.55(0.18-1.71)$ & 0.300 & $1.21(0.30-4.85)$ & 0.786 \\
\hline Others Undelivered & $1.89(0.091-0.39)$ & 0.865 & $1.66(0.50-5.55)$ & 0.407 \\
\hline \multicolumn{5}{|l|}{ Province: } \\
\hline Ref: Central & $\operatorname{Ref}(1)$ & & $\operatorname{Ref}(1)$ & \\
\hline Eastern & $0.63(0.38-1.38)$ & 0.08 & $0.61(0.35-1.09)$ & 0.09 \\
\hline Luapula & $0.76(0.46-1.25)$ & 0.275 & $0.21(0.07-0.58)$ & 0.003 \\
\hline Lusaka & $4.64(3.21-6.69)$ & $<0.0001$ & $0.07(0.001-0.51)$ & 0.008 \\
\hline Northwestern & $1.06(0.51-2.16)$ & 0.883 & $0.81(0.40-1.63)$ & 0.55 \\
\hline Northern & $0.00(0)$ & 0.98 & $0.00(0)$ & 0.98 \\
\hline Southern & $1.03(0.64-1.66)$ & 0.90 & $0.86(0.53-1.39)$ & 0.54 \\
\hline Western & $0.50(0.28-0.92)$ & 0.026 & $0.44(0.24-0.81)$ & 0.008 \\
\hline \multicolumn{5}{|l|}{ HIV $^{2}$ Status: } \\
\hline Ref: HIV Positive & $\operatorname{Ref}(1)$ & & $\operatorname{Ref}(1)$ & 0.24 \\
\hline HIV Negative & $0.59(0.46-0.75)$ & $<0.0001 *$ & $1.32(0.83-2.08)$ & \\
\hline \multicolumn{5}{|l|}{ Cause of Death: } \\
\hline Ref: Abortions & Ref (1) & & $\operatorname{Ref}(1)$ & \\
\hline Haemorrhage & $2.01(0.83-4.83)$ & 0.12 & $0.52(0.19-1.43)$ & 0.21 \\
\hline Hypertensive & $0.08(0.33-0.2 .33)$ & 0.79 & $0.20(0.07-0.61)$ & 0.005 \\
\hline Others & $1.06(0.43-2.65)$ & 0.90 & $0.22(0.08-0.63)$ & 0.004 \\
\hline
\end{tabular}

Others=Other indirect causes; 2=HIV-Human Immunodeficiency Virus

1 Ref-Reference Variable

2 HIV-Human immunodeficiency virus 


\section{Discussion}

The study aimed to assess the trends and associated factors of maternal mortality in Zambia and the findings were that there was a steady trend of maternal deaths in the four-year period with not much differences in the highs and lows of the deaths over the study period. The factors that contributed to maternal deaths were cause of death which included hypertensive disorders, sepsis, and indirect causes like malaria or tuberculosis. Other factors included province and age. The study shows that the women with sepsis have a reduced risk of maternal death compared to women who aborted.

Interestingly, the last months of the four-year period had downward trends. The findings of downward trend in December 2015 in this study could have been attributed to the nation's attempts and efforts in meeting the MDG number $5 \mathrm{a}$ which aimed to reduce maternal mortality by $75 \%$ between 1990 and 2015. Towards the conclusion of the MDGs, a number of initiatives were established to galvanize efforts towards reducing maternal mortality. Building on the momentum generated by MDG 5, the SDGs establish a transformative new agenda for maternal health towards ending preventable maternal mortality; target 3.1 of SDG 3 by 2030 [8].

Majority of the deaths were in the age group of 20-29 years and 30-39 years. In Zimbabwe [9] and United States [10] findings show that increase in age, increased incidence of maternal death in women. However, other studies have argued that maternal deaths are higher in the age group 11-18 and this is in comparison to the age group $25-29$ years old [11].

Luapula, Western and Lusaka province had decreased chances of maternal death compared to Central province. These findings are consistent with those from Zambia Statistics Agency where they found that at a provincial level, Western province maternal mortality ratio was $(786 / 100,000)$, Lusaka province $(343 / 100000)$ and Luapula province $(573 / 100000)$ [12]. In the survey, it was noted that the differences shown in the numbers of the deaths could be related to the geographical variation and differences in socioeconomic, environmental, and demographic features in the provinces.

Indirect causes of death were a factor to maternal mortality. Various studies have shown that having a history of preexisting medical conditions contributed to maternal mortality [13]. A study done in Zambia [14] on maternal mortality trends found that $28.3 \%$ of the deaths in the study were due to indirect causes. This showed that over a quarter of the deaths that occurred where due to the indirect causes which could be due to a possibility that they were overlooked in pregnant women. Similarly, a study done in Tanzania found that malaria accounted for the highest number of maternal deaths at $13 \%$ of the total mortality burden (2,348 deaths), then cardiovascular diseases accounted for $10 \%$ of the total deaths, HIV/AIDS and pneumonia had $8 \%$ of deaths while anaemia accounted for $6 \%$ [15]. In a systematic review done on global causes of maternal deaths, it was found that more than a quarter of deaths were attributable to indirect causes [16].

Sepsis in this study was a protective factor to maternal death which is contrary to various studies that have shown that maternal sepsis accounts for $11 \%$ of all maternal deaths in the world. It is the third most common factor of maternal death and contributes greatly to other factors that lead to maternal death [17]. Sepsis could occur post-abortal or could be infections after caesarean section or normal delivery in the puerperal period. Similar findings by WHO [18] were that sepsis was among the seven major causes of maternal death. In Northern Nigeria, sepsis was among the leading causes of maternal deaths [19]. Early diagnosis and intervention could be key in saving lives and prevention of maternal deaths from sepsis.

Hypertension, haemorrhage, and sepsis are responsible for more than half of maternal deaths worldwide. However, we noted that more than a quarter of deaths were attributable to indirect causes. In Rwanda, more than half of the maternal deaths were due to direct causes of which haemorrhage and Hypertensive disorders were among them [22]. On the other hand in South Africa, hypertension related maternal deaths and the HIV status was not different between the HIV positive and HIV negative mothers [20]. However, other studies have argued that women living with HIV in subSaharan Africa are approximately 8 times as likely to die during pregnancy or the postpartum period as HIV-negative women [21]. Nonetheless, 30 days of antiretroviral therapy before delivery has been found to be associated with reduced risk of death during childbirth and postpartum [22].

WHO and USAID reports have shown that HIV, malaria, and opportunistic infections like pneumonia contributes a large proportion of maternal deaths where these conditions are prevalent like in sub-Saharan Africa [4]. Maternal death remains a serious problem not only in Zambia but also in developing countries. Thus, factors associated with maternal deaths revealed in the study and suggested factors from other studies may likely give a better picture of maternal deaths in developing countries.

\section{Conclusion}

The study has found that maternal death has been relatively high and steady from 2015 to 2019. The risk of maternal death was higher among women who had aborted, women of higher age group and women situated in central province, whereas Sepsis in the study had a decreased risk of maternal death. The findings also established that the significant factors of maternal deaths were province, Age, indirect causes, hypertensive disorders and sepsis. Women who had live births had an increased IRR compared to those who had abortions. In the study, HIV status of the woman was not associated to maternal death. 


\section{Recommendations}

To reduce maternal mortalities, improvement of maternal health while focusing on appropriate and timely interventions are key. There is need to strengthen targeted care and careful screening of pregnant women with medical conditions so that risk factors and medical conditions are identified and treated early, to make the pregnant women stable during pregnancy and be able to withstand the stress of pregnancy and labour using trained and skilled health care workers. New policies and guidelines to support antibiotic therapy post-delivery to reduce maternal sepsis, enhancing community involvement, education, and awareness on importance of seeking health services early in pregnancy especially if one has an underlying medical condition and on postpartum care to prevent postnatal sepsis.

Proper practice of infection prevention and control by health care workers to prevent sepsis. Early referral for management of hypertensive disorders following referral guidelines like in the EmNOC, monitoring of health status of pregnant women and individualised care in the management of hypertensive disorders. Improvement in recording of information in health facility records should be given adequate attention during data collection. There is also need for capturing of information on mothers that survive after delivery so that more studies could be done to know on which type of women are dying and which ones are surviving.

\section{Strengths and Limitations of the Study}

The observations used for analysis were large enough and the results produced could be useful for planning, restrategizing, and finding suitable models for reducing maternal deaths in Zambia.

The study however, encountered limitations during data extraction, analysis, and interpretation. The use of secondary data in the study limited control over the quality of data that was collected, and the other potential limitations were missing observations on most variables.

\section{Author Contribution}

N. C Musonda and C. Jacobs formulated the initial idea for this study, N. C Musonda, C. Jacobs, M. Chola and P. Kaonga contributed to writing up the project plan. N. C. Musonda and S. Shumba collected the data. N. C Musonda, S. Shumba and P. Kaonga contributed to data analysis. The write up and final manuscript was done by all the authors.

\section{Conflict of Interest}

The author declares no conflict of interest.

\section{Acknowledgements}

Department of Epidemiology and Biostatistics, School of Public Health University of Zambia.
Ministry of Health, M \& E department for providing the data.

Chama Kasonde for his insightful input during data cleaning.

NORPART grant for partly funding this research.

\section{References}

[1] WORLD HEALTH ORGANIZATION (2004). International statistical classification of diseases and related health problems: Instruction manual. World Health Organization, Geneva.

[2] WORLD HEALTH ORGANIZATION. (2019). Trends in maternal mortality 2000 to 2017: estimates by WHO, UNICEF, UNFPA, World Bank Group and the United Nations Population Division. World Health Organization. https://apps.who.int/iris/handle/10665/327595. License: CC BY-NC-SA 3.0 IGO.

[3] GIRUM, T., WASIE, A. Correlates of maternal mortality in developing countries: an ecological study in 82 countries. matern health, neonatol and perinatol 3, 19 (2017). https://doi.org/10.1186/s40748-017-0059-8.

[4] COLBOURN, T., LEWYCKA, S., NAMBIAR, B., ANWAR, I., PHOYA, A., \& MHANGO, C. (2013). Maternal mortality in Malawi, 1977-2012. BMJ open, 3 (12), e004150. https://doi.org/10.1136/bmjopen-2013-004150.

[5] CENTRAL STATISTICAL OFFICE (CSO) [ZAMBIA], MINISTRY OF HEALTH (MOH) [ZAMBIA], AND ICF INTERNATIONAL. 2014. Zambia Demographic and Health Survey 2013-14. Rockville, Maryland, USA: Central Statistical Office, Ministry of Health, and ICF International.

[6] ZAMBIA NATIONAL STRATEGIC HEALTH PLAN (ZNHSP) 2017-2021. Ministry of Health, Government of Zambia. 2017.

[7] WHO, UNICEF, UNFPA, World Bank Group and the United Nations Population Division: a2015 Trends in maternal mortality between 1990 to 2015: ISBN 9789241565141 .

[8] HEALTH 2015: from MDGs-millennium development goals to SDGs-sustainable development goals, Geneva, World Health Organization.

[9] COURAGE MAMBO, C. C. A. T. Z. N., 2013 November, 2013. An Investigation of the causes of maternal mortality in Zimbabwe. Mediterranean Journal of Social Sciences. Italy., Volume 4. No 14.

[10] CALlaghan WM AND BERG CJ, Pregnancy-related mortality among women aged 35 years and older, United States, 1991-1997, Obstetrics \& Gynecology, 2003, 102 (5): 1015-1021.

[11] CAVAZOS-REHG, P. A., KRAUSS, M. J., SPITZNAGEL, E. L., BOMMARITO, K., MADDEN, T., OLSEN, M. A., SUBRAMANIAM, H., PEIPERT, J. F., \& BIERUT, L. J. (2015). Maternal age and risk of labor and delivery complications. Maternal and child health journal, 19 (6), 1202-1211. https://doi.org/10.1007/s10995-014-1624-7.

[12] CENTRAL STATISTICAL OFFICE (CSO) [Zambia], 2012. 
[13] YEGO, F., D'ESTE, C., BYLES, J., WILLIAMS, J. S. \& NYONGESA, P. 2014. Risk factors for maternal mortality in a Tertiary Hospital in Kenya: a case control study. $B M C$ Pregnancy Childbirth, 14, 38.

[14] GIANETT B, MUSAKANYA KE, NGOMAH MORAES A, CHIZUNI C, GROENEVELD C, KAPINA M, HAMOONGA R, MAZABA ML, MUKONKA V. Maternal mortality trends and correlates in Zambia. Health Press Zambia Bull. 2019; 3 (4 \& 5); pp 12-16.

[15] MANYEH, A. K., NATHAN, R. \& NELSON, G. 2018. Maternal mortality in Ifakara Health and Demographic Surveillance System: Spatial patterns, trends and risk factors, 2006 - 2010. PloS one, 13, e0205370-e0205370.

[16] SAY, L., CHOU, D., GEMMILl, A., TUNCALP, O., MOLLER, A. B., DANIELS, J., GULMEZOGLU, A. M., TEMMERMAN, M. \& ALKEMA, L. 2014. Global causes of maternal death: a WHO systematic analysis. Lancet Glob Health, 2, e323-33.

[17] ALI, A., \& LAMONT, R. F. (2019). Recent advances in the diagnosis and management of sepsis in pregnancy. F1000Research, 8, F1000 Faculty Rev-1546. https://doi.org/10.12688/f1000research.18736.1.
[18] WORLD HEALTH ORGANIZATION (2010). The World Health Report 2010. https://www.who.int/publications/i/item/9789241564021.

[19] MAIRIGA, A. G. \& SALEH, W. 2009. Maternal mortality at the State Specialist Hospital Bauchi, Northern Nigeria. East Afr Med J, 86, 25-30.

[20] ONYANGUNGA OA, NAICKER TA, MOODLEY J. Maternal and perinatal outcomes after caesarean delivery in early and late onset preeclampsia with HIV positive and HIV negative South African Women. Niger J Clin Pract. 2019; 22 (5): 591-597. doi: 10.4103/njcp.njcp_364_16.

[21] MYER, L. 2013. Maternal deaths and HIV treatment in subSaharan Africa. Lancet, 381, 1699-700.

[22] LIOTTA, G., MANCINELLI, S., NIELSEN-SAINES, K., GENNARO, E., SCARCELLA, P., MAGID, N. A., GERMANO, P., JERE, H., GUIDOTTI, G., BUONOMO, E., CICCACCI, F., PALOMBI, L. \& MARAZZI, M. C. 2013. Reduction of Maternal Mortality with Highly Active Antiretroviral Therapy in a Large Cohort of HIV-Infected Pregnant Women in Malawi and Mozambique. PLOS ONE, 8, e71653. 